\title{
Outcome analysis of ulnar shortening osteotomy for ulnar impaction syndrome
}

\author{
Courtney Fulton BSc ${ }^{1}$, Ruby Grewal MD MSc FRCSC ${ }^{1,2}$, Kenneth J Faber MD MHPE FRCSC ${ }^{1,2}$, \\ James Roth MD FRCSC FACS ${ }^{1,2}$, Bing Siang Gan MD PhD FRCSC FACS $1,2,3,4$
}

\author{
C Fulton, R Grewal, KJ Faber, J Roth, BS Gan. Outcome analysis \\ of ulnar shortening osteotomy for ulnar impaction syndrome. Can J \\ Plast Surg 2012;20(1):e1-e5.
}

BACKGROUND: Ulnar-sided wrist pain is a common problem in the upper extremity. It affects a broad patient population and can be difficult to treat. Ulnar impaction syndrome (UIS) is major cause of ulnar-sided wrist pain and a number of different operations have been used to correct it, including ulnar shortening osteotomy (USO).

OBJECTIVE: To retrospectively review functional outcomes and complication rates of USO for UIS at the Hand and Upper Limb Centre (London, Ontario) over a two-year period.

METHODS: Twenty-eight patients who underwent USO between 2007 and 2009 participated in the present study. Ulnar variance pre- and postsurgery was assessed using standard radiographic examination. Patientrated outcomes were measured using a visual analogue scale (VAS) for pain and the Disabilities of the Arm, Shoulder and Hand (DASH) survey for functional outcomes. Objective grip strength and range of motion were compared with the contralateral extremity.

RESULTS: On average, USO achieved a $3.11 \mathrm{~mm}$ reduction in ulnar variance. Nonunion occurred in five patients and required a secondary bone grafting procedure. All USO eventually healed. Overall, pain improved by $47.2 \%$ and the mean DASH score after surgery was 37.21 . Flexion, extension and supination range of motion decreased by $10^{\circ}$ compared with the unaffected side. Eleven patients (39\%) elected to undergo a second surgery for hardware removal. Patients receiving compensation from the Workplace Safety and Insurance Board experienced significantly higher residual pain (VSA 5.24 versus 1.97) and disability levels (DASH 60.23 versus 25.70). Smokers also experienced worse outcomes in terms of pain (VSA 4.43 versus 2.36) and disability (DASH 51.06 versus 29.67). In this cohort, smoking was not associated with a higher rate of nonunion.

CONCLUSION: USO is effective in reducing pain in UIS and improves disability, at the price of a small decrease in range of motion. Smokers and people receiving compensation from the Workplace Safety and Insurance Board, however, have significantly worse subjective outcomes (VAS and DASH), but similar objective outcomes (range of motion).

Key Words: Ulnar impaction syndrome (UIS); Ulnar shortening osteotomy (USO); Ulnar wrist pain

\section{L'analyse d'issue de l'ostéotomie de raccourcissement du cubitus en cas de syndrome d'impaction ulnaire}

HISTORIQUE : La douleur au cubitus du poignet est un problème courant des membres supérieurs. Elle touche une grande population de patients et peut être difficile à traiter. Le syndrome d'impaction ulnaire (SIU) est une cause importante de douleur au cubitus du poignet. Diverses opérations ont été utilisées pour la corriger, y compris l'ostéotomie de raccourcissement ulnaire (ORU).

OBJECTIF : Procéder à l'analyse rétrospective des issues fonctionnelles et des taux de complication d'ORU du SIU au Hand and Upper Limb Centre de London, en Ontario, sur une période de deux ans.

MÉTHODOLOGIE : Vingt-huit patients qui ont subi une ORU entre 2007 et 2009 ont participé à la présente étude. Les chercheurs ont évalué la variance ulnaire avant et après l'opération au moyen d'un examen radiographique classique. Ils ont mesuré les issues classées par les patients au moyen d'une échelle analogique visuelle (ÉAV) de la douleur et du sondage DASH sur les incapacités du bras, de l'épaule et de la main évaluant les issues fonctionnelles. Ils ont comparé la force de préhension et l'amplitude de mouvement objectives à celles du membre controlatéral.

RÉSULTATS : En moyenne, l'ORU a permis d'obtenir une réduction de 3,1 mm de la variance ulnaire. Chez cinq patients, une non-fusion a exigé une greffe osseuse secondaire. Toutes les ORU ont fini par guérir. Dans l'ensemble, la douleur a diminué de $47,2 \%$, et l'indice DASH moyen après l'opération s'élevait à 37,21. L'amplitude de flexion, d'extension et de supination a diminué de $10^{\circ}$ par rapport au côté non touché. Onze patients (39\%) ont choisi de subir une deuxième opération afin d'extraire les tiges de métal. Les patients indemnisés par la Commission de la sécurité professionnelle et de l'assurance contre les accidents du travail ressentaient une douleur résiduelle (ÉAV de 5,24 par rapport à 1,97) et des taux d'invalidité (DASH de 60,23 par rapport à 25,70) considérablement plus élevés. Les fumeurs présentaient également une issue moins favorable sur le plan de la douleur (ÉAV de 4,43 par rapport à 2,36) et de l'invalidité (DASH de 51,06 par rapport à 29,67). Au sein de cette cohorte, le tabagisme ne s'associait pas à un taux plus élevé de nonfusion.

CONCLUSION : L'ORU est efficace pour réduire la douleur en cas de SIU et amenuise l'incapacité au prix d'une légère diminution de l'amplitude de mouvement. Les fumeurs et les personnes indemnisées par la Commission de la sécurité professionnelle et de l'assurance contre les accidents du travail, cependant, ont une issue subjective bien pire (ÉAV et DASH), mais une issue objective similaire (amplitude de mouvement).

A common cause of ulnar-sided wrist pain is UIS. This entity is believed to occur secondary to ulnar head compression against the TFCC and ulnar carpus, leading to degeneration of these structures $(2,5)$. UIS is also known as ulnocarpal abutment syndrome and was described as early as 1941 by Henry Milch $(3,6)$.

The treatment of UIS includes nonoperative options such as intermittent immobilization, nonsteroidal anti-inflammatory drugs, avoidance of ulnar deviation and steroid injections (1). If this fails, there are currently three surgical options: the arthroscopic 'wafer' procedure, ulnar shortening osteotomy (USO) and hemiresection arthroplasty. The surgical treatments are based on the theory that shortening the ulna will decrease the load on the TFCC (3). Previous work has shown that an increase in the ulnar variance of only $2.5 \mathrm{~mm}$ can increase the axial load on the forearm by $40 \%$, whereas a decrease of $2.5 \mathrm{~mm}$ can
Dain on the ulnar side of the wrist is common and can arise from acute trauma, chronic degeneration or overuse (1). The ulnar side complex anatomy, the extensive differential diagnosis and difficulty in treatment (1). Ulnar-sided wrist pain can be frustrating to manage for both the patient and the physician, especially because significant pain can be present without any radiographic cause (2). The differential diagnosis in patients with ulnar-sided wrist pain includes ulnar impaction syndrome (UIS), degenerative arthritis, triangular fibrocartilage complex (TFCC) pathology, carpal ligament tears and instability, extensor carpi ulnaris (ECU) and flexor carpi ulnaris tendinosis, and incongruity of the distal radioulnar joint (DRUJ) $(3,4)$. The extensive range of etiologies of pain is associated with a broad age group. In the younger age groups, it is often associated with vocational injuries.

${ }^{1}$ The Hand and Upper Limb Centre; ${ }^{2}$ Department of Surgery; ${ }^{3}$ Divisions of Orthopaedic and Plastic Surgery; ${ }^{4}$ Department of Medical Biophysics,

Schulich School of Medicine and Dentistry, University of Western Ontario, London, Ontario

Correspondence: Dr Bing Siang Gan, The Hand and Upper Limb Centre, St Joseph's Health Centre, Suite D0-215,

268 Grosvenor Street, London, Ontario N6A 4L6. Telephone 519-646-6097, fax 519-646-6049, e-mail bsgan@rogers.com 
How severe is your pain today? Place a vertical mark on the line below to indicate how bad your pain is today.

TODAY:

No pain I I Worst Pain

Please also make a vertical mark to indicate how bad your pain was BEFORE surgery.

\section{BEFORE SURGERY:}

No pain I

Worst Pain

Figure 1) Visual analogue scale for pain. This was given to all patients during follow-up. Patients were asked to mark the horizontal line in correspondence to their pain perception

decrease the axial load down to 5\% (3). A number of factors need to be considered when selecting a procedure to treat UIS, including the amount of ulnar variance, the status of the TFCC, the shape of the sigmoid fossa and the ulnar seat (2). However, there is no consensus as to which factor is most important in deciding what procedure to perform in each case, and personal preference plays an important role in procedure selection (7).

One study found that after arthroscopic TFCC debridement, there was a significant proportion of patients who still experienced pain and subsequently were required to undergo USO (8). There was no difference in the initial presentation in patients with successful versus unsuccessful debridement. The arthroscopic wafer procedure was designed to shorten the ulna arthroscopically through a torn TFCC. The advantage of this procedure is that it is minimally invasive (9). However, the wafer procedure can only be performed if there is a tear in the TFCC. In addition, it is very difficult to repair or tighten the ulnocarpal ligament complex, and recovery often takes longer than six months $(1,9)$. USO maintains the cartilage surface at the distal ulna and has the benefit of tightening the ulnocarpal ligament complex. Disadvantages include the possibility of inducing or aggravating DRUJ incongruency. Osteotomy also carries the risk of nonunion and a possible later requirement for hardware removal $(7,9)$. Newer hardware devices for USO may help with the latter two complications $(9,10)$. When UIS is already complicated by DRUJ incongruency or degenerative arthritis, the DRUJ hemiresection arthroplasty, or one of its variations, is preferred (10).

At the The Hand and Upper Limb Centre (London, Ontario), the largest hand surgery unit in Canada, USO is the most commonly performed surgical treatment for UIS. While we have been generally satisfied with our outcomes, we have yet to perform a detailed analysis of our patient cohort. The goal of the current study was to characterize the self-reported outcomes of patients who underwent USO surgery in terms of pain (using a visual analogue scale [VAS]) and function (using the Disabilities of the Arm and Shoulder [DASH] survey), and to complement these data with objective radiological and range of motion (ROM) measurements.

\section{METHODS}

All patients at the The Hand and Upper Limb Centre, who underwent USO between 2007 and 2009, were contacted for the present study in total, 50 individuals were treated by four different surgeons. The only exclusion criterion was age younger than 18 years at the time of the present review. Of these 50 patients, 28 consented to participate in all or part of the study.

A retrospective chart review was conducted to determine patient demographic characteristics and complication rates. Pre- and postoperative radiographs were reviewed to determine change in static ulnar variance and confirm union. Standard wrist posteroanterior radiographs were taken with the shoulder in $90^{\circ}$ abduction, elbow in $90^{\circ}$ flexion, and forearm in neutral pronation and supination. Ulnar variance was measured by projecting a line perpendicular to the long axis of the radius at the ulnar portion of the lunate facet of the distal radius toward the ulna, and projecting a line perpendicular to the long axis of the ulna at the level of the articular surface of the ulnar head. The axial difference between these lines was then measured (2). This measurement is independent of the length of the ulnar styloid (2). In the case of nonunion requiring revision of the USO, the analyzed ulnar variance was taken after the final surgery.

Patients self-reported pain using a VAS (Figure 1) and self-reported functional outcome using the DASH survey. In addition, the patient's grip strength and ROM were measured by an independent observer. Patients who were unavailable for clinical assessment were asked to complete the VAS and DASH surveys only (six of 28 subjects). The VAS was scored from 0 (no pain) to 10 (maximal pain), and was standardized at $10 \mathrm{~cm}$. The DASH survey has been previously validated to provide a reliable estimate of a patient's self-reported outcome in terms of pain and function. In the DASH survey, outcome is measured from 0 to 100 , with lower scores corresponding to less disability. Grip strength was recorded in kilograms using a JAMAR dynamometer (Lafayette Insrument, USA) on both the operated hand and contralateral hand. Patients were asked to grip the dynamometer three consecutive times. ROM measurements were performed using a goniometer. Wrist extension and flexion were measured with a protocol known to provide reliable results for dorsal placement of the goniometer. Pronation and supination were measured by aligning the arm of the goniometer with the superior side of the arm along specific anatomical landmarks. These landmarks are the proximal wrist crease for supination and just distal to the ulnar head in pronation. The other goniometer arm was aligned with the vertical plane. Ulnar and radial deviation was measured with the patient's arm flat on the table in pronation, using the radius as the pivot point. All measurements were performed by one investigator (CF) to reduce intraobserver variability.

Student's paired $t$ tests were used to compare the ROM of affected and unaffected sides as well as VAS at the time of final follow-up. Student's unpaired $t$ tests were used to assess potential differences between the following groups: Workplace Safety and Insurance Board (WSIB) and non-WSIB patients, men and women, and patients older and younger than 50 years of age. Fisher's exact tests were performed to evaluate nonparametric factors within groups.

\section{Surgical procedure}

USO was conducted under regional or general anesthetic. Under tourniquet control, a longitudinal incision was made on the ulnar border of the wrist. The interval between the flexor carpi ulnaris and the ECU muscle was excised and the ECU was retracted dorsally. A $3.5 \mathrm{~mm}$ low contact dynamic compression plate (Synthes Corporation, USA) was applied to the bone, usually on the palmar aspect of the wrist, but occasionally on the dorsal side if anatomy was more favourable. Distal screws were inserted before osteotomy and the osteotomy site was marked. A single longitudinal groove was used as a mark to control rotation. The amount of shortening was determined on the basis of preoperative radiographs, with the goal of restoring an approximate normal $2 \mathrm{~mm}$ negative variance. An oblique $45^{\circ}$ osteotomy was performed. The plate was subsequently resecured distally and the proximal screws were placed using dynamic compression. Rotation was controlled by realigning the previously created longitudinal groove. Several patients had an oblique lag screw placed across the osteotomy site. The periosteum and skin were closed with vicryl and nylon sutures, respectively. The wound was dressed and patients wore a forearm cast for eight to 12 weeks.

In the case of nonunion, repeat surgery was performed. The original incision was reopened and the nonunion area was debrided. A new osteotomy was performed to create fresh bone ends to realign the ulna. Iliac crest or Allomatrix (Wright Medical Technologies, USA) bone graft was used to augment the union.

In four patients, arthroscopy was performed at the time of USO. Standard 3-4, 4-5 or $6 \mathrm{U}$ arthroscopy portals were used for the procedure. Sterile saline was injected into the joint and the TFCC was debrided under direct vision. After debridement, the USO surgery continued as described above. 


\begin{tabular}{|c|c|c|}
\hline \multicolumn{3}{|c|}{$\begin{array}{l}\text { Patient demographics and surgical parameters related to } \\
\text { ulnar shortening osteotomy. Overall outcome values }\end{array}$} \\
\hline & Mean & $\mathbf{n}$ \\
\hline Age, years & 48.11 & 28 \\
\hline Follow-up, months & 21.24 & 28 \\
\hline Pain before (/10) & 7.85 & 28 \\
\hline Pain after $(/ 10)$ & 3.14 & 28 \\
\hline DASH & 37.21 & 27 \\
\hline DASH: Work & 38.44 & 20 \\
\hline DASH: Sports & 50.41 & 14 \\
\hline Ulnar variance before, $\mathrm{mm}$ & 2.32 & 28 \\
\hline Ulnar variance after, $\mathrm{mm}$ & -0.79 & 28 \\
\hline Grip strength affected hand, kg & 21.27 & 22 \\
\hline Grip strength opposite hand, kg & 29.27 & 22 \\
\hline
\end{tabular}

DASH Disabilities of the Arm, Shoulder, and Hand survey. Score out of 100, lower scores = less disability. The work and sports sections were optional in the survey, leading to lower $n$ numbers

\section{RESULTS}

Demographics

Twenty-eight people consented to participate in all or part of the present study. Demographic characteristics are summarized in Tables 1 and 2 . The average age was 48 years (range 18 to 74 years) and average follow-up was 22 months (range eight to 41 months). Nineteen of the patients were female and nine were male. Ten patients were involved in WSIB claims. The majority of patients injured their dominant hand (17 of 28), and in a traumatic incident (23 of 28). Only 12 of the patients had a diagnosed TFCC tear.

\section{Surgical characteristics}

All patients underwent USO by one of four surgeons after a clinical diagnosis of UIS. Twenty-six of the patients had documented positive ulnar variance, one was ulnar negative and one was ulnar neutral, with an average positive ulnar variance of $2.32 \mathrm{~mm}$ (SEM $0.37 \mathrm{~mm}$ ). Three patients underwent a separate arthroscopy procedure before USO, four had arthroscopy simultaneous with USO, and one underwent arthroscopy after USO. ROM comparisons with the contralateral extremity were not performed in three patients who underwent unrelated surgery on the opposite hand. Two patients were scheduled to undergo USO on the opposite side in the future.

\section{Clinical outcomes}

The average preoperative VAS was 7.85 and improved to 3.14 postoperatively $(\mathrm{P}<0.0001)$ - a $47.2 \%$ improvement. The average DASH score at follow up was 37.21 (range 1 to 79). Flexion, extension and supination $\mathrm{ROM}$ were statistically significantly decreased $(\mathrm{P}<0.05)$ by approximately $10^{\circ}$ each (Table 3 ). Radial and ulnar deviation, and pronation were comparable with the 'normal' contralateral side. Grip strength was an average of $21.27 \mathrm{~kg}$ on the operated side and $29.47 \mathrm{~kg}$ on the contralateral side. At the time of final analysis, 11 people had undergone or were scheduled to undergo hardware removal (39\%), which is similar to that reported in other studies.

\section{Complications}

Possible complications of USO included nonunion and need for hardware removal at a later date due to hardware irritation. There was a nonunion rate of $18 \%$ (five patients), which is higher than the previously published rates of $1 \%$ to $4 \%(12,13)$. One patient had a delayed union. One patient developed complex regional pain syndrome. Another patient developed symptoms of carpal tunnel syndrome.

\section{Subgroup analysis}

Subgroup analysis was performed to determine whether previously established criteria that have been shown to affect outcome also applied to this patient population. Subgroup analysis was performed as
TABLE 2

Patient characteristics $(n=28)$

\begin{tabular}{lr}
\hline Dominant hand & $\mathbf{n}(\%)$ \\
Female & $17(60.71)$ \\
WSIB & $19(67.86)$ \\
Smoker $(\mathrm{n}=27)$ & $10(35.71)$ \\
Trauma & $10(37.04)$ \\
Arthroscopy & $23(82.14)$ \\
Exogen* low-intensity pulsed ultrasound & $4(14.29)$ \\
Malunion rate & $2(7.14)$ \\
Hardware removal & $5(17.86)$ \\
\hline
\end{tabular}

*Smith \& Nephew, United Kingdom. WSIB Workplace Safety and Insurance Board (workers' compensation)

TABLE 3

Overall range of motion (ROM)

\begin{tabular}{|c|c|c|c|c|}
\hline \multirow[b]{2}{*}{ ROM } & \multicolumn{2}{|c|}{ Hand } & \multirow[b]{2}{*}{ Normal, \% } & \multirow[b]{2}{*}{$\mathbf{P}$} \\
\hline & Affected & Opposite & & \\
\hline Extension & 46.52 & 56.50 & 85.33 & 0.026 \\
\hline Flexion & 53.00 & 63.25 & 84.60 & 0.022 \\
\hline Ulnar deviation & 34.83 & 38.25 & 93.69 & 0.307 \\
\hline Radial deviation & 23.83 & 27.80 & 92.86 & 0.209 \\
\hline Pronation & 61.39 & 71.45 & 93.68 & 0.088 \\
\hline Supination & 67.00 & 78.85 & 86.87 & 0.041 \\
\hline
\end{tabular}

ROM measurements in six directions presented in degrees unless otherwise indicated. Only extension, flexion and supination reached statistical significance

to whether the patient was receiving workers' compensation (WSIB versus non-WSIB, Tables 4 and 5); age older than versus younger than 50 years, females versus males, and smoking status. No statistical differences were found based on age or most comparisons between men and women. Women had higher pain before surgery (VAS 8.47 versus $6.55, \mathrm{P}=0.041$ ); however, pain scores were the same after surgery for both men and women. In addition, women had significantly less grip strength in both the operated and contralateral hand; however, the per cent normal ratio was not different between men and women. Major differences were found between the WSIB and non-WSIB groups. Although both groups had similar pain before surgery according to their VAS scores ( 7.37 versus $8.12, \mathrm{P}=0.186)$, WSIB patients reported significantly more pain after surgery (5.24 versus $1.97, \mathrm{P}=0.0002)$. As well, all three DASH scores measured (overall, work and sports) were significantly higher in the WSIB group (Table 4). All demographic characteristics were similar between the two groups except for smoking status. Seven of 10 WSIB patients smoked compared with only three of 18 in the non-WSIB group. When the smoking and nonsmoking patients were divided and compared, there was a significant $(\mathrm{P}<0.05)$ difference in the following categories: pain after surgery, DASH scores overall and work, and grip strength. ROM measurements were the same in all groups analyzed and showed no differences in WSIB and smokers.

\section{DISCUSSION}

The present retrospective study had several inherent limitations. The preoperative pain assessments were subject to patient recall bias. In addition, because there were no complete preoperative ROM measurements available, we had to compare postoperative ROM values with the contralateral side. Similarly, preoperative DASH scores for some patients were unavailable and, therefore, only residual disabilities were measured. Notwithstanding these shortcomings, our data appear to characterize an typical cohort of USO patients at our centre. While we did not attain full participation from all 50 patients who underwent a USO between 2007 and 2009, we believe the group of 28 that participated accurately reflect the total group of patients. One major factor that affected our ability to recruit patients was the large geographical 
TABLE 4

Group analysis - Workers' compensation

\begin{tabular}{lrcccccc}
\hline & \multicolumn{2}{c}{$\begin{array}{c}\text { Non-WSIB } \\
\text { (n=18) }\end{array}$} & & \multicolumn{2}{c}{ WSIB } \\
\cline { 2 - 3 } & Mean=10) & SEM & & Mean & SEM & P \\
\hline Age & 48.89 & 3.98 & & 46.70 & 3.01 & 0.664 \\
Female, \% & 77.78 & - & & 50.00 & - & 0.173 \\
Smoker, \% & 17.64 & - & & 70.00 & - & 0.011 \\
Follow-up, months & 22.94 & 2.44 & & 20.3 & 3.46 & 0.540 \\
Pain before (/10) & 8.12 & 0.32 & & 7.37 & 0.74 & 0.186 \\
Pain after (/10) & 1.97 & 0.51 & & 5.24 & 0.76 & 0.0002 \\
DASH & 25.70 & 4.93 & & 60.23 & 4.70 & 0.0000 \\
DASH: Work & 22.11 & 6.96 & & 68.75 & 9.25 & 0.0008 \\
DASH: Sports & 31.19 & 14.06 & & 85.00 & 10.00 & 0.004 \\
Ulnar variance before, mm & 2.72 & 0.36 & & 1.60 & 0.78 & 0.215 \\
Ulnar variance after, mm & -0.33 & 0.44 & & -0.85 & 0.69 & 0.538 \\
Grip strength affected hand, kg & 23.15 & 2.65 & & 19.00 & 3.68 & 0.361 \\
Grip strength opp hand, kg & 30.60 & 3.12 & & 29.50 & 5.51 & 0.731 \\
Grip strength \% normal & 71.98 & - & & 85.31 & - & 0.485 \\
\hline
\end{tabular}

Subgroup analysis of patients undergoing ulnar shortening osteotomy. Workers Safety and Insurance Board (WSIB) versus non-WSIB analysis shows significant differences in the incidence of smoking, and Disabilities of the Arm, Shoulder, and Hand survey (DASH) outcome scores. Other surgical outcome parameters are equal in this analysis. DASH score out of 100 , lower score = less disability

distribution of the patients, with some patients having to travel more than $8 \mathrm{~h}$ to return to clinic. Unless these patients were already scheduled for follow-up appointments, they were unlikely to want to travel for our study.

A VAS was used to measure patient perception of pain along a continuous $10 \mathrm{~cm}$ line (Figure 1). This is similar to many other pain measurement tools that do not have the limitations of discrete values. With this tool, we attempted to gauge the difference in pre- and postsurgery pain for each patient. We found a significant average decrease in overall pain when comparing pain recalled before surgery to pain at the time of follow-up; however, pain did not improve in $21 \%$ of the patients in our study. Three patients reported a slight increase in pain following surgery, one said there was no change, and two experienced improvements of less than $1 \mathrm{~cm}$ on the $10 \mathrm{~cm}$ VAS. Of these six patients, five were smokers, were receiving WSIB compensation, or both. This supports our hypotheses that not only do these patients do worse, but also that these two groups (smoking and WSIB) are very difficult to separate. Six patients reported zero pain after surgery; all of these patients were nonsmokers and did not receive WSIB compensation. In addition, women were found to have significantly different pain scores from men presurgery, but this was not the case for postsurgery pain. This could be due to sex-related differences in pain sensitivities, but may also be due to a variances in recall bias.

The DASH survey was also used to record subjective patient outcomes. This 30-item regional questionnaire was developed in 1996 as a tool to measure disability in the upper limb and monitor its change over time (11). In our study, we used it to measure residual disability and to compare patients in different subgroups. Not surprisingly, patients who reported less pain on the VAS tended to have lower DASH scores. In addition, there was a wide range in functional outcomes (DASH, range 1 to 79) despite the low average level of residual disability (mean DASH of 37.21). Two patients with zero pain after surgery still found that they experienced significant functional problems, and one patient with an excellent functional result $(\mathrm{DASH}<10)$ experienced more pain than would be expected (VAS 2.9). Currently, we warn our patients that functional outcomes, while generally good, do not always correlate with pain reduction.
TABLE 5

Group analysis - Comparing range of motion between WSIB and non-WSIB groups

\begin{tabular}{lcccccc}
\hline \multirow{2}{*}{$\begin{array}{l}\text { Range of } \\
\text { motion }\end{array}$} & \multicolumn{2}{c}{ Non-WSIB } & & \multicolumn{3}{c}{ WSIB } \\
\cline { 2 - 3 } & $\begin{array}{c}\text { Affected } \\
\text { hand }\end{array}$ & $\begin{array}{c}\text { Opposite } \\
\text { hand }\end{array}$ & & $\begin{array}{c}\text { Affected } \\
\text { hand }\end{array}$ & $\begin{array}{c}\text { Opposite } \\
\text { hand }\end{array}$ & P \\
\hline Extension & 51.00 & 58.80 & & 40.70 & 54.20 & 0.709 \\
Flexion & 57.54 & 67.60 & & 47.10 & 58.90 & 0.822 \\
Ulnar deviation & 41.08 & 43.10 & & 26.70 & 33.40 & 0.589 \\
Radial deviation & 28.31 & 28.20 & & 18.00 & 27.40 & 0.102 \\
Pronation & 60.38 & 73.90 & & 62.70 & 69.00 & 0.737 \\
Supination & 69.15 & 82.80 & & 64.20 & 74.90 & 0.869 \\
\hline
\end{tabular}

Data presented as degrees unless otherwise indicated. Subgroup analysis of patients undergoing ulnar shortening osteotomy. Workerplace Safety and Insurance Board (WSIB) versus non-WSIB analysis shows no significant differences in the functional range of motion measurements in six directions

We also measured ROM and grip strength to have objective measurements to complement the self-reported patient outcomes. On average, patients had grip strength of approximately $80 \%$ of their nonoperated hand. Women and men had similar per cent normal ratios when comparing operated and nonoperated hands; however, women had lower overall grip strength. Of the six directions of ROM, flexion, extension and supination were diminished in the operated hand, and only by $10^{\circ}$ each. This indicates a low residual deficit after surgery, but it would have been helpful to note the grip strength and ROM presurgery to see how much, if any, gains patients made in these areas. The presence or absence of hardware on the patient's wrist had no significant effect on ROM. This was expected because the plate should not hinder joint articulation; patients that were extremely irritated by the hardware would have likely had it removed by the follow-up visit.

We report a higher nonunion rate than previously reported in the literature. This could be due to the broad inclusion criteria of the study, the older average age, or the fact that most of the nonunion patients were still being followed in the clinic and, therefore, easier to recruit for the present study. This higher number could thus result from selection bias. The rate of nonunion in all 50 patients who underwent USO was lower (14\%). In addition, because 22 of 50 patients did not consent to participate in the present study, it may be possible that patients who experienced no problems and were doing well, did not feel a compelling reason to participate. It is possible that smoking status led to a higher nonunion rate, as other studies have reported, but this was not a statistically significant result in the current study (12).

In our review, WSIB patients and smokers were both found to have worse outcomes, which is consistent with many other recent studies, thus lending validity to our results (12-16). These patient populations overlap significantly and it is difficult to determine which factor contributes more to patient outcomes. It has long been known that smoking affects healing after surgery. Chen et al (12) specifically examined smoking and bony union after USO and found that smokers took, on average, three months longer to heal than nonsmokers. We did not specifically investigate the duration of the healing process in our patient population. In the study by Chen et al (12), 30\% of smokers, compared with zero nonsmokers, experienced a nonunion (12). Ziran et al (15) also found smoking status affected bone graft and Allomatrix effectiveness. Interestingly, in our study, smoking and WSIB status were not significantly associated with higher nonunion rates. Only five people experienced a nonunion and our sample size may have been too small to detect a difference in union rates between groups. Workers' compensation is slightly more complicated to explain because it does not have a direct physiological correlation to healing. Several recent studies on upper limb surgery and outcomes have found that people receiving worker's compensation (WSIB) compensation 
were more likely to have poor outcomes and need repeat surgeries $(13,14,16)$. Iwasaki et al $(14)$ postulated that socioeconomic factors and highly physically demanding jobs may explain this difference. A retrospective study on shoulder outcomes after rotator cuff repairs found that both smoking and WSIB played a major role in patient outcomes and predicted worse results (13). In this study, both worker's compensation (WSIB) and non-compesation (non-WSIB) patients were found to have similar pain scores presurgery to controls, but more WSIB patients had more pain postsurgery. This cannot be explained by a functional deficit because no differences were found in ROM or grip strength when compared with the other patients in the study. Our study thus supports patient factors as the likely cause for the difference in outcomes. Patients with an active worker's compensation claim may internalize a worsened view of their function and their own assessment of how well they can recover. These speculations are difficult to analyze objectively, and it is possible that no one will be able to pinpoint a specific modifiable risk factor that correlates to WSIB status. Nevertheless, both of these can be used as prognostic indicators and help with presurgery counselling of patients when USO is being considered as a treatment option.

\section{REFERENCES}

1. Sachar K. Ulnar-sided wrist pain: Evaluation and treatment of triangular fibrocartilage complex tears, ulnocarpal impaction syndrome, and lunotriquetral ligament tears. J Hand Surg 2008;33:1669-79.

2. Cerezal L, del Pinal F, Abascal F, et al. Imaging findings in ulnarsided wrist impaction syndromes. Radiographics 2002;22:105-21.

3. Bernstein MA, Nagle DJ, Martinez A, Stogin JM Jr, Wiedrich TA. A comparison of combined arthroscopic triangular fibrocartilage complex debridement and arthroscopic wafer distal ulna resection versus arthroscopic triangular fibrocartilage complex debridement and ulnar shortening osteotomy for ulnocarpal abutment syndrome. Arthroscopy 2004;20:392-401.

4. Bickel KD. Arthroscopic treatment of ulnar impaction syndrome. J Hand Surg 2008;33:1420-3.

5. Friedman SL, Palmer AK. The ulnar impaction syndrome. Hand Clin 1991;7:295-310.

6. Milch H. Cuff resection of the ulna for malunited Colles' fracture. J Bone Joint Surg 1941;23:311-3.

7. Watanabe A, Souza F, Vezeridis PS, Blazar P, Yoshioka H. Ulnar-sided wrist pain. II. Clinical imaging and treatment. Skeletal Radiol 2010;39:837-57.

8. Hulsizer D, Weiss AP, Akelman E. Ulna-shortening osteotomy after failed arthroscopic debridement of the triangular fibrocartilage complex. J Hand Surg 1997;22:694-8.

9. Tatebe M, Nakamura R, Horii E, Nakao E. Results of ulnar shortening osteotomy for ulnocarpal impaction syndrome in wrists
The next step in this research would be to perform a prospective trial to allow presurgery values to be collected and then compared with postsurgery results for a more comprehensive look at the outcomes for USO.

\section{CONCLUSION}

After USO, pain improved overall by $47.2 \%$ and the mean DASH score was 37.21, indicating a low level of residual disability. Extension, flexion and supination were decreased by approximately $10^{\circ}$ compared with the unaffected side, but there were no differences found in ROM during group analysis. Patients receiving workers' compensation and smokers were likely to experience higher residual pain and disability levels, both of which were contributing factors in seven of 28 patients.

DISCLOSURE: The authors have no financial interest in the material presented in this article.

with neutral or negative ulnar variance. J Hand Surg $\mathrm{Br}$ 2005;30:129-32.

10. Kitzinger HB, Karle B, Low S, Krimmer H. Ulnar shortening osteotomy with a premounted sliding-hole plate. Ann Plast Surg 2007;58:636-9.

11. Hudak PL, Amadio PC, Bombardier C. Development of an upper extremity outcome measure: The DASH (Disabilities of the Arm, Shoulder and Hand) [corrected]. The Upper Extremity Collaborative Group (UECG). Am J Ind Med 1996;29:602-8.

12. Chen F, Osterman AL, Mahony K. Smoking and bony union after ulna-shortening osteotomy. Am J Orthop (Belle Mead NJ) 2001;30:486-9.

13. McRae S, Leiter J, Walmsley C, Rehsia S, Macdonald P. Relationship between self-reported shoulder function/quality of life, body mass index, and other contributing factors in patients awaiting rotator cuff repair surgery. J Shoulder Elbow Surg 2010;20:57-61.

14. Iwasaki N, Ishikawa J, Kato H, Minami M, Minami A. Factors affecting results of ulnar shortening for ulnar impaction syndrome. Clin Orthop Relat Res 2007;465:215-9.

15. Ziran BH, Hendi P, Smith WR, Westerheide K, Agudelo JF. Osseous healing with a composite of allograft and demineralized bone matrix: adverse effects of smoking. Am J Orthop (Belle Mead NJ) 2007;36:207-9.

16. Duncan SF, Calandruccio JH, Merritt MV, Crockarell JR, Kakinoki R. A comparison of workers' compensation patients and nonworkers' compensation patients undergoing endoscopic carpal tunnel release. Hand Surg 2010;15:75-80. 